\title{
ASSISTÊNCIA MÉDICA PARA IMIGRANTES REQUERENTES DE PROTEÇÃO. UM DIREITO UNIVERSAL À SAÚDE ? ${ }^{1}$
}

\section{MEDICAL ASSISTANCE FOR INTERNATIONAL PROTECTION APPLICANTS. HEALTH AS AN UNIVERSAL RIGHT?}

María Dolores Requena de Torre ${ }^{2}$

\begin{abstract}
Resumo: De acordo com a observação n. 14 do Comitê de Assuntos Econômicos, Sociais e Culturais, a saúde é um direito humano fundamental e indispensável ao exercício de outros direitos humanos. É por isso que todo ser humano tem o direito de disfrutar do mais alto nível de saúde possível que lhe permita viver com dignidade. Na mesma linha, este direito é reconhecido a cada pessoa no artigo 25 da DUDH, o artigo 12 do PIDESC e artigo 35 CDFUE. Apesar disso, a atual crise migratória, somada a sequela da ainda recente crise econômica, pôs em discussão a reconhecimento desse direito, subordinando-o ao pagamento de assistência a certos grupos, incluindo aquele que nos preocupa aqui: imigrantes irregulares. Embora seja verdade que tanto estes como os requerentes de proteção internacional têm a garantia de assistência de emergência, o que pretendemos examinar aqui é como essa limitação, que se beneficia da natureza complexa desse direito, coloca em questão algo ainda mais sério: a dignidade das pessoas. Revisamos para isso a controversa sentença 139/2016 do Tribunal Constitucional espanhol e terminamos com uma última abordagem com uma estreita relação: o direito à proteção da saúde pode atuar como um limite para a expulsão de um imigrante?
\end{abstract}

Palavras-chave: Assistência médica. Saúde universal. Imigrante. Real Decreto-Lei 16/2012. STC 139/2016.

\begin{abstract}
:
According to the observation No. 14 of the Committee of Economical, Social and Cultural rights, health is an essential human right in the execution of other human rights. For this reason, every human being has the right to enjoy the highest attainable standard of health that allow them living with dignity. In the same line, that right is recognized to every individual in the article 25 of the UDHR; the article 12 of ICESCR and the article 35 of CFREU. In spite of this fact, the current migratory crisis, in addition to the consequences of the recent economical crisis, set to debate the recognition of that right, conditioning the payment of healthcare assistance for certain groups, including those that concern us here: migrants in irregular situation. Even though both, these and the international protection seeker have emergency assistance guaranteed, our aim here is to scope how that limitation, which takes advantage of the complex nature of that right, questions something even more worrying: individuals dignity. For achieving that goal, we analyzed the controverted sentence 139/2016 of the Spanish Constitutional Court concluding with a close related point: Could the healthcare right be one of the limits that could lead to an immigrant expelling?
\end{abstract}

Keywords: Universal heathcare. Inmigrant. RDL-16/2012; STC139/2016.

Recebido em 6 de fevereiro de 2020 Aceito em 20 de abril de 2020

\footnotetext{
1 Traduzido por Eduardo Bonamigo; Mestre em Direito pela Universidade do Oeste de Santa Catarina (UNOESC). Servidor público federal e professor da UNOESC. E-mail: edubonamigo@yahoo.com.br

2 Mestra em Direito da União Europeia pela Universidade Nacional de Educación a Distância; Mestra em Direitos Fundamentais em uma Perspectiva Nacional, Supranacional e Global pela Universidade de Granada; Contratada predoctoral en la Universidad de Granada con la ayuda FPU del Ministerio de Educación; Plaza de la Universidad, s/n., 18001, Granada, Espanha; https://orcid.org/0000-0002-2609-2594; lolarequena@.ugr.es
} 


\section{Introdução: crise migratória e crise de valores}

Afirmava Monereo Pérez e Triguero Martínez (2016, p. 12), que desde a última grande guerra, nunca se questionou tão diretamente e frontalmente os princípios e valores que subjazem e cristalizam os direitos humanos. Nos últimos anos, a Europa viveu duas grandes crises: a primeira, uma devastadora crise econômica sem precedentes, e a segunda, uma crise migratória que, sobretudo a partir de 2015, ultrapassou a União Europeia com uma normativa que não estava preparada para isso.

Ambas as crises tiveram consequências muito semelhantes: um aumento da tensão entre os Estados-Membros, o questionamento dos valores fundamentais da União e, em grande medida, se colocou em dúvida que exista uma verdadeira "Comunidade do Direito".

Sem dúvida, todo o sofrimento provocado pela crise econômica e pelas medidas de economia influenciou no tratamento dado a imigrantes e requerentes de proteção internacional. Nesse sentido, a crise do Estado social, prova ou consequência da crise econômica, tem uma de suas maiores manifestações na gestão pela União Europeia e pelos seus Estados-Membros desta grave crise humanitária que supõem os movimentos migratórios massivos dos últimos anos. A decepcionante recepção dessas pessoas por um sistema mais próprio de uma Comunidade Econômica que de uma Comunidade de Direito evidencia um falso dilema que já se instalou em uma parte importante da população europeia, e que parece apresentar a imigração como uma encruzilhada entre o humanitário e o pragmático (LUCAS MARTÍN, 2016). Um dilema que se estende as garantias de nossos direitos a imigrantes e refugiados em detrimento de nossa segurança e bem-estar. No entanto, o que realmente assistimos é um desmantelamento do âmbito de reconhecimento e da garantia de direitos humanos. ${ }^{3}$ Um desamparo que é o resultado de uma mudança na lógica governante que desde o fim da Segunda Guerra Mundial tratava de ser uma lógica inclusiva para passar a ser agora de exclusão ou, para o tema que nos ocupa, de expulsão.

A proteção judicial eficaz, o acesso à saúde, à liberdade, à educação ou à reunificação familiar são apenas alguns dos direitos que estão sendo questionados tanto pelas práticas dos diferentes Estados como pelas propostas de reforma do SECA (Sistema Europeu Comum de Asilo), reafirmando o que Hannah Arendt disse no século passado, que o direito ao asilo se configurou em um direito a ter direitos; e é que, enquanto não se conceder asilo ou proteção subsidiária, ou que se decida pelo seu regresso, milhões de pessoas, incluindo crianças, vivem em campos de refugiados, em centros de internamento, ou na própria rua, visto que em muitos casos, vendo a maioria de seus direitos básicos sendo ignorados, sendo privados da liberdade ao serem tratados como criminosos, cujo único crime tem sido a busca pela sobrevivência.

Isto porque a política da UE em matéria de migração dirigida as nacionalidades de países de terceiro mundo condiciona certos direitos dos migrantes ao reconhecimento de asilo ou a proteção

\footnotetext{
Entrevista a Ruiz Jiménez en la revista digital Agora.
} 
subsidiária. Desta forma, acontece com as pessoas cujo destino ainda não foi decidido pelo Estado receptor, que seus direitos fundamentais são ignorados, ou relegados a uma espécie de limbo que, mesmo submetendo-se à jurisdição de um Estado membro, este não se encarrega de por causa de sua situação de "irregulares", ficando o reconhecimento daqueles direitos por parte do Estado em situação de pendência, dependendo de se reconhecer a proteção e, por conseguinte, os direitos, ou, pelo contrário, de acordar sua expulsão.

Este trabalho enfoca o direito à saúde (ou proteção à saúde) que, segundo o Relator Especial das Nações Unidas, "impõe aos Estados obrigações de efeito imediato que se sobrepõem. Entre elas se incluem obrigações imediatas de não discriminar e de tomar medidas, a obrigação de garantia básica dos níveis mínimos essenciais do direito, e as obrigações de respeitar e proteger. As obrigações imediatas estão fora do o escopo do artigo 2 do Pacto Internacional sobre Desenvolvimento Econômico, Social e Cultural. As obrigações básicas são o nível mínimo essencial de um direito e elas não são realizadas de modo progressivo. As obrigações de respeitar e proteger são similares as obrigações em virtude do Pacto Internacional de Direitos Civis e Políticos de respeitar e garantir (porque o dever de garantir inclui o dever de proteger), que são indiscutivelmente judiciáveis. Estas obrigações de efeito imediato podem depender, de fato, dos recursos para sua aplicação. [...] (Mas) mesmo que uma obrigação de efeito imediato dependa de recursos, o Estado não pode usar a falta de recursos como uma defesa ou desculpa para não cumprir a obrigação. ${ }^{4}$

Apesar disso, e como será percebido ao longo deste trabalho, a garantia deste direito tem sido subordinada a critérios econômicos nos últimos anos, sacrificando uma parte dos grupos mais vulneráveis: imigrantes em situação administrativa irregular e requerentes de proteção internacional. Uma prova a mais da penosa situação que sofrem estas pessoas quando chegam a Europa pode ser resumida na fórmula onomatopeica formulada por Lucas Martín (2017), "vás aonde vás, cercas."

\section{Assistência médica: Um direito a saúde? Precisões terminológicas}

Devemos começar esta seção com cautela sobre a denominação a ser usada na mesma: o artigo 43 da Constituição espanhola, que está dentro do Capítulo III do Título I, sob a declaração "dos princípios orientadores da política social e econômica" (CONSTITUCIÓN ESPAÑOLA, 1978) tem um conteúdo amplo e uma natureza complexa. Este preceito reconhece o direito à proteção da saúde (Artigo 43.1); declara que cabe às autoridades públicas organizar e proteger a saúde pública através de medidas preventivas, das prestações e serviços necessários comuns mandato ao legislador para que se estabeleçam os direitos e deveres de todos (Artigo 43.2); e indica que as autoridades públicas promovem a educação em saúde, educação física e esporte, facilitando o uso adequado do tempo livre (Artigo 43.3).

\footnotetext{
4 Informe del Relator Especial de Naciones Unidas. Documento A/69/299, de 11 de agosto de 2014, p. 5. Disponível em: https://undocs.org/pdf? symbol=es/A/69/299. Acesso em: 20 out. 2019.
} 
Como observamos anteriormente, sua natureza é complexa quando situada no Capítulo III. A nível internacional, a saúde está prevista em numerosos textos como um direito universal. Assim, o Artigo 35 da CDFUE; o Artigo 25 da Declaração Universal dos Direitos Humanos; ou o Artigo 12 do Pacto Internacional de Direitos Econômicos, Sociais e Culturais. No entanto, na Espanha, a colocação pelo Constituinte do "direito de proteção à saúde", no capítulo III, diferencia-o intencionalmente dos direitos civis e políticos e direitos fundamentais, colocando-o como "Princípio orientador", consagrando o que alguns autores chamaram de desvalorização jurídica dos direitos sociais própria das constituições liberais (MARTÍNEZ DE PISÓN, 2006, p. 129-150).A delimitação da natureza desse direito não é objeto deste trabalho. Por agora basta dizer que a proteção à saúde é um direito de prestação, não fundamental. Acontece, então, que a proteção reforçada que merece é concedida apelando para o princípio da dignidade da pessoa, não só como suposta condição de fundação dos direitos; mas também para contribuir para a sua definição e reconhecimento, bem como iluminar a criação ou descoberta de novos espaços jusfundamentais (PORRAS RAMÍREZ, 2018, p. 214). E não só com dignidade, mas pela dificuldade em especificar esse conceito, o direito à saúde foi vinculado intimamente com o Artigo $15 \mathrm{CE}$, isto é, o direito à integridade física. É tal a confluência entre os dois preceitos que, muitas vezes, traz prejuízos ou riscos relevantes para este que foi objeto do procedimento de amparo pela conexão com o direito fundamental do Artigo 15 (SANTIAGO REDONDO, 2018, p. 1345).

\section{Um direito universal? Comentário à STC 139/2016}

Em 2012, foi aprovado o Real Decreto-Lei n. 16/2012, de 20 de abril, 5 de medidas urgentes para garantir a sustentabilidade do Sistema Nacional de Saúde e melhorar a qualidade e a segurança de seus benefícios (doravante, RDL). Entre as modificações incluídas na norma se encontra a exclusão como "assegurado" daquelas pessoas estrangeiras não membros da UE sem autorização da residência. Para estes imigrantes em situação irregular a assistência médica gratuita ficou limitada ao tratamento de urgência ou de doença grave até a alta médica e a assistência a gravidez, parto e pós-parto; e aos menores estrangeiros de 18 anos o direito à assistência médica nas mesmas condições que a dos espanhóis.

Não se pretende aqui analisar a RDL, nem a reação das Comunidades Autônomas ante isso. Nos basta dizer que nove comunidades aplicaram, de forma diversa, tal exclusão a estrangeiros em situação irregular; Aragão, Ilhas Baleares, as Ilhas Canárias, Cantábria, Castela-Mancha e Múrcia aplicaram-na de forma rigorosa e outro grupo de Comunidades formado por Castela e Leão, Comunidade de Valencia, Galiza e Navarra permitiram a atenção aos estrangeiros irregulares no mínimo estabelecido. Finalmente, um grupo minoritário formado pela Andaluzia, Astúrias, a Catalunha e o País Basco rejeitaram a sua aplicação desde o início (SOLANES CORELLA, 2014).O que

5 Real Decreto que havia sido revogado pelo Real Decreto-Lei n. 7/2018, de 27 de julho, sobre o acesso universal ao Sistema Nacional de Saúde. 
nos interessa é a resposta que deu o Tribunal Constitucional a esta medida limitativa e excludente, num contexto de crise econômica. Assim, em 2016, o Tribunal Constitucional resolveu o recurso de inconstitucionalidade pelo Parlamento de Navarra contra esta medida de exclusão. A controversa Sentença 139/2016 rejeitou o motivo e por isso foi encaminhada à jurisprudência CJEU, alegando que o artigo 35 da CDFUE refere-se ao direito de pessoa para cuidados de saúde, nas condições estabelecidas pelas legislações e práticas nacionais; o que implica aceitar a prática confirmada pelo Tribunal de Justiça para observar a regularidade da residência do imigrante para delimitar o acesso a certos benefícios sociais para salvaguardar a necessidade das finanças do Estado de acolhimento (STJUE, Sala Primeira, 14 de junho de 2016, e doutrina ali citada).

Em seu julgamento, o Tribunal afirmou, com base em uma jurisprudência consolidada, que

a natureza do direito à saúde como princípio orientador não implica que o art. $43 \mathrm{CE}$ constitua uma norma puramente programática, desprovida de conteúdo, sem referências que a informam, especialmente em relação ao legislador, que deve configurá-la em virtude do configurá-lo sob o mandato do art. $43.2 \mathrm{CE}$ para que estabeleça os benefícios necessários para proteger a saúde pública. (ESPANHA, 2016b).

E ele continuou assegurando a universalidade do direito à proteção da saúde e aos cuidados de saúde, que, segundo o Tribunal, implica o acesso aos serviços públicos de saúde enquanto ninguém pode ser excluído do direito de ser atendido. No entanto, se insiste na sentença da "falta de identidade entre o direito de acesso universal ao sistema público de saúde daquele 'todo' do art. 43 CE, com que o acesso à saúde pública inclui o benefício de um regime específico de benefícios de saúde gratuitos ou subsidiados a cargo de fundos públicos." (ESPANHA, 2016b).

Com base nesta diferenciação, o Tribunal reconhece que os poderes públicos devem garantir a proteção da saúde organizando as prestações e serviços necessários. No entanto, isso não implicaria que estas devam ser gratuitas para todos os seus potenciais destinatários devendo ser a legislação a que determine o alcance dessa gratuidade, de acordo com as exigências decorrentes das circunstâncias em mudança, respeitando os limites constitucionais. Pois, encontrando-se o artigo $43^{\circ} \mathrm{CE}$ no Capítulo III do Título I da Constituição, o Tribunal insistiu em recordar o inerente componente de flexibilidade que caracteriza o quadro constitucional e que confere ao legislador uma ampla margem de configuração.

Neste sentido, a universalização legislativa proclamada no quadro normativo preexistente é considerada pelo TC simplesmente como um objetivo a alcançar que, em todo caso, deve atender às circunstâncias e, em particular e de forma notável, as circunstâncias econômicas. De acordo com o Tribunal, a universalidade como direito de acesso e a sua correlativa obrigação dos serviços de saúde do Sistema Nacional de Saúde de atender aos usuários não pode ser confundida com um 
direito à gratuidade nas prestações e nos serviços de saúde, pois isso não decorre de forma imediata da Constituição espanhola.

Em relação às alterações do regime de cuidados de saúde aos estrangeiros registrados sem autorização de residência, o Tribunal justificou a exclusão ao considerar que o direito à proteção da saúde não é um direito inerente à dignidade humana que, por conseguinte, deve corresponder igualmente a espanhóis e estrangeiros, mas que faz parte de um grupo de direitos que pertencerão ou não aos estrangeiros, conforme o disponham os tratados e leis.

O Tribunal parece ter identificado este direito à proteção da saúde como um direito prestacional de plena configuração legal de tal forma que

para além de rejeitar uma vinculação entre a vocação universalista presente no artigo $43 \mathrm{CE}$ como um direito incondicionado à gratuidade das prestações, a sentença não fornece qualquer orientação interpretativa ulterior que determine constitucionalmente o que deve ser entendido ou entendido como acesso universal. $\mathrm{Na}$ prática, por tanto, parece inferir-se que a universalidade terá o conteúdo que o legislador (ordinário ou de urgência) confie a tal conceito em cada momento. (SOBRINO GUIJARRO, 2017, p. 85).

O que parece ignorar esta falha, e a Diretiva 2013/33, relativa às regras de acolhimento dos requerentes de proteção e que será discutida posteriormente, é que este direito de prestação, inspirado nos princípios de "igualdade material" e de "justiça distributiva" (art 9.2 CE), enquanto componentes essenciais de um Estado que se autoqualifica como social e democrático de direito (art. 1.1 CE), responde ao fim constitucional de garantir a todos uma "digna qualidade de vida". Daí que o Estado se dote das competências e instrumentos necessários para satisfazê-los, em benefício especial daqueles que inicialmente não se encontram em condições de acessar por si mesmos aos bens e serviços que pressupõem. Razão pela qual cabe ao Estado intervir tomando todas as medidas que considere necessárias para assegurar, aos que as precisem, as "oportunidades de liberdade", ou seja, as condições necessárias de existência digna que não podem alcançar por si só (PORRAS RAMÍREZ, 2018, p. 215). Esta é a principal utilidade do princípio da dignidade humana; dotar de pleno reconhecimento os direitos de prestação, mal intencionalmente desprotegidos; enquanto que, desde que apelamos à dignidade humana, não pode haver discriminação entre seres humanos, seja por nacionalidade, por condição social ou por situação administrativa irregular.

Muito interessante é a reflexão de A. M. Marcos, ao questionar-se que sentido tem reconhecer outros direitos fundamentais aos estrangeiros, como o direito de reunião ou de associação, se a impossibilidade de acesso ao sistema de saúde reduz as suas capacidades físicas e psíquicas para aceder a esses direitos (MARCOS DEL CANO, 2017). A saúde configura-se assim como uma condição de viabilidade para o exercício de suas liberdades ) (CÁRCAR BENITO, 2016); e ao estabelecimento de um sistema público e de acesso universal é, portanto, uma garantia para salvaguardar a dignidade humana, pois, nas palavras do Tribunal Constitucional, a dignidade é o "mínimum invulnerável que qualquer estatuto jurídico deve assegurar, de modo que as limitações impostas ao gozo de direitos 
individuais não impliquem um menosprezo para a estima que, enquanto ser humano, merece a pessoa." (STC 57/1994 de 28 de fevereiro, FJ.3) (MARCOS DEL CANO, 2017). E, ainda, o TC nos Autos 239/2012, de 12 de dezembro, 114/2014 de 8 de abril e 54/2016 de 1 de março em referência à inconstitucionalidade de uma norma, precisamente pela violação da universalidade,

pondera a proporcionalidade das medidas estabelecidas com o seu impacto no artigo 43 da CE, fazendo referência ao interesse geral da sustentabilidade financeira do sistema de saúde público e às reduções econômicas decorrentes destas medidas e, pelo outro, os danos que possam ser causados na saúde pública e em indivíduos específicos. (MARCOS DEL CANO, 2017). ${ }^{6}$

Não obstante, o Tribunal considerou que a manutenção da assistência de emergência e da gravidez salvaguarda o conteúdo essencial do direito, o mandato imperativo de prestação dos poderes públicos do artigo $43^{\circ} \mathrm{CE}$ e os compromissos decorrentes dos Tratados internacionais (SOBRINO GUIJARRO, 2017). No entanto, é mais do que questionável que esse julgamento necessário de proporcionalidade que exigia o caso, ao que nos referimos antes, e no qual se baseavam as críticas da advogada do Parlamento Navarro e em torno ao qual giram os Votos Particulares.

Nesta linha, a sentença do Tribunal Constitucional 236/2007 estabelece uma doutrina consolidada segundo a qual, as condições de exercício que o legislador estabelece em relação aos direitos dos estrangeiros "só serão constitucionalmente válidas se, respeitando o seu conteúdo essencial, se destinarem a preservar outros direitos, bens ou interesses constitucionalmente protegidos e guardarem adequadamente com a proporção dependente da finalidade pretendida." (SOBRINO GUIJARRO, 2017). No entanto, o Tribunal apenas menciona a proporcionalidade uma vez: no Fundamento Jurídico 10, e na ausência de uma maior explicação dessa consideração limita-se a afirmar que

a norma examinada não responde a uma opção arbitrária, mas à preservação de bens ou interesses constitucionalmente protegidos como a manutenção do sistema de saúde público [...] observando-se na distinção entre estrangeiros com autorização de residência e os que dela não dispõem, com a proporcionalidade adequada [...]. (SOBRINO GUIJARRO, ${ }^{2017}$ ).

\footnotetext{
6 A autora se remete ainda para o argumento utilizado pelo Tribunal Constitucional para levantar a suspensão do decreto impugnado do País Basco que entendia a cobertura sanitária dos imigrantes irregulares. De acordo com o FJ. 5, "Tendo em conta a concretização dos prejuízos decorrentes do levantamento ou da manutenção da suspensão efetuada pelas partes, bem como a importância dos juros em jogo e apreciando este Tribunal que o direito à saúde e o direito à integridade física das pessoas afetadas pelas medidas impugnadas, bem como a conveniência de evitar riscos para a saúde do conjunto da sociedade, têm uma importância singular no quadro constitucional, que não pode ser desvirtuada pela mera consideração de uma eventual economia financeira que não pôde ser concretizada, entendemos que se justifica o levantamento da suspensão da vigência dos preceitos relativos à ampliação do âmbito sujeito do direito a aceder à assistência sanitária pública e gratuita." (SOBRINO GUIJARRO, 2017, p. 85). Um pronunciamento ignorado na STC 139/2016.
} 


\subsection{Votos individuais}

Perante a depressiva falha, a sentença recebeu dois votos individuais que, entre as diferentes motivações pelas quais discordavam da decisão da maioria, salientavam precisamente a desproporcionalidade da medida, principalmente por não ser coerente com o seu fim e por se dirigir a um coletivo particularmente vulnerável tanto pela sua condição administrativa como pela sua situação econômica.

O primeiro voto, subscrito pelo Magistrado D. Fernando Valdés Dal-Re, parte por questionar o uso do Real Decreto-Lei, do qual se entende que nem se justificou o orçamento de extraordinária e urgente necessidade; nem respeitou os limites materiais do artigo 86.1 do Tratado CE.

Neste sentido, o Magistrado questiona o argumento dado na Sentença segundo o qual o direito à saúde, dada a sua localização sistemática na Constituição "não possui as características de direito cuja regulamentação por Decreto-Lei impede o artigo 86.1." (ESPANHA, 2016a). Pelo contrário, o Magistrado Váldes Dal-Ré considera que a proibição de afetação longe de definir um domínio vedado à atividade legislativa do Governo tem uma função de servir de limite interno tanto da estrutura da norma como do conteúdo normado pela disposição legal com carácter de urgência. Além disso, o raciocínio do Tribunal neste ponto obviaria as duas ideias básicas que contribuíram para a consolidação da noção de direitos tout court, ou seja, a indivisibilidade de todos os direitos, independentemente do seu conteúdo e da conexão e instrumentalidade de certos direitos ou princípios constitucionais "não fundamentais" em respeito a outros que o são por se situarem no capítulo II do título I.

Nessa linha argumentativa, o Magistrado parte de uma comparação entre o direito à tutela judicial efetiva, e o direito ao a poio judiciário gratuito, cuja titularidade foi reconhecida aos estrangeiros independentemente do seu estado jurídico com base nessa ligação instrumental (STC90/2015). Por conseguinte, e no mesmo sentido, também o direito à saúde do artigo 43 CE desenvolve uma relação de Instrumentalidade com um direito fundamental, o direito à vida e à integridade física e moral do artigo 15 CE. Uma ligação instrumental que já tem sido reiteradamente assinalada pelo Tribunal Constitucional e pelo TEDH e que permite concluir que os direitos dos cidadãos reconhecidos no Título I CE são afetados por um Decreto-Lei que afeta diretamente a saúde. E, por tanto, o Real Decreto-Lei devia respeitar o limite material de não afetação dos elementos essenciais.

Não ocorreu assim, e o próprio preâmbulo da norma dá prova disso desde o momento em que afirma que "as medidas que se aplicam no presente Real Decreto- Lei tem como objetivo fundamental uma reforma estrutural do Sistema Nacional de Saúde." (ESPANHA, 2012). E que confirma um exame das modificações introduzidas como a modificação do âmbito subjetivo e objetivo.

Mas mesmo que se afirme que se fez um uso adequado do Decreto-Lei, o raciocínio mais importante para o tema que nos ocupa é: o legislador pode excluir um coletivo de um sistema universal e gratuito (mesmo que seja uma gratuidade relativa) cujo objetivo é assegurar um direito 
adequado à saúde? Além disso, pode essa exclusão de um coletivo basear-se na sua nacionalidade ou mesmo na sua condição administrativa ligada à residência legal? $\bigcirc$ Tribunal, no acordo da maior parte da clássica divisão tripartida em matéria de titularidade e exercício dos direitos dos estrangeiros em Espanha e segundo o qual o legislador pode estabelecer restrições e limitações a alguns direitos, no entanto a STC 236/2007 já observou que "esta possibilidade não é incondicionada na medida em que não poderá afetar aqueles direitos imprescindíveis para a garantia da dignidade humana que, conforme o art. 10.1 CE, constitui fundamento da ordem política espanhola" nem, adicionalmente, "ao conteúdo delimitado pelo direito, a Constituição ou os tratados internacionais subscritos pela Espanha." (ESPANHA, 2007b). Além disso,

a liberdade do legislador também é restringida na medida em que as condições de exercício que estabelece em relação aos direitos e liberdades dos estrangeiros em Espanha só serão constitucionalmente válidas se, respeitando seu conteúdo essencial (Art. 53.1 CE), visem preservar outros direitos, bens ou interesses constitucionalmente protegidos e guardam adequada proporcionalidade com a finalidade perseguida. (STC 236/2007 FJ 4). (ESPANHA, 2007b).

Em suma, e tal como defende o Magistrado Valdés Dal-Ré, para determinar se a exclusão dos imigrantes sem autorização de residência do sistema público de saúde é compatível com o reconhecimento do direito à saúde, é mais razoável admitir que, podendo ser introduzidos limites ao exercício dos direitos, é necessário que os mesmos estejam previstos na lei, sejam necessários numa sociedade democrática e sejam proporcionais ao fim que pretendem, conforme estabelecido na base jurídica 4 da STC 236/2007. Uma proporcionalidade que não se verifica neste caso ao excluir um coletivo que, na sua grande maioria, carece de meios econômicos de modo que presumivelmente não pagará o serviço público, nem recorrerá a um serviço privado, mas que finalmente irá ao serviço público por urgências.

No que se refere à falta de coerência, basta referir que numerosos estudos, como o da Agência Europeia dos Direitos, concluíram que os Estados-Membros gastam menos em cuidados de saúde dos migrantes se forem tratados antes em vez de esperar que necessitem de tratamento em emergências (EUROPEAN UNION AGENCY FOR FUNDAMENTAL RIGHTS, 2015).No entanto, este argumento, mesmo que seja o contrário, deveria ser desprovido de importância num Estado social desde que se trata de uma medida a um coletivo em risco de exclusão social, cuja falta de recursos econômicos põe em risco a sua saúde e integridade, afastando-os de uma verdadeira assistência médica. Tal como afirmou o magistrado D. Fernando Valdés Dal-Ré "talvez esse risco não seja grave, porque nesses casos podem recorrer à assistência de emergência; mas esta avaliação só pode ser verificada a posteriori, quando o dano à saúde já tenha ocorrido, dano este que, em muitas ocasiões, pode ser já irreversível." 


\section{Direito à proteção da saúde e requerentes de proteção internacional}

Apesar de a alínea anterior ter se centrado nos imigrantes em situação irregular por serem os principais afetados pelo RDL, importa salientar que tudo o que foi dito é extrapolado para a saúde dos requerentes de proteção internacional, uma vez que o Artigo $19^{\circ}$ da Diretiva 2013/33 estabelece a obrigação de os Estados-Membros de assegurar a prestação de cuidados de saúde necessários aos requerentes. Trata-se de uma norma de mínimos cujo objetivo é proteger os cuidados de emergência e o tratamento básico de doenças ou transtornos psíquicos graves, e que nos leva a interrogar-nos de novo se o garantir uma saúde de urgência, e não em igualdade de condições em relação aos nacionais, está em conformidade com a efetiva garantia do direito à proteção da saúde e da própria dignidade humana.

Embora a universalidade do acesso às prestações de saúde não seja explicitamente proclamada, não pode ser ignorada desde que colocamos a dignidade da pessoa como limite à sua configuração. Ou seja, perante o exercício do direito à proteção da saúde, a sua eventual modulação pelo legislador deve sempre observar, e como primeiro parâmetro, a garantia da dignidade humana, o que nos leva a duvidar que este acesso limitado seja compatível com a lógica dos direitos humanos.

A dignidade como pressuposto antropológico da Configuração do Estado social e democrático de Direito e base comum do conjunto dos Direitos humanos, e também, portanto, da proteção da saúde, requereria cuidados de saúde completos enquanto decorre ou processo de reconhecimento do Direito de asilo, sem qualquer discriminação. Isto é, se o Direito à proteção da saúde pertence à pessoa, dada a relação intrínseca entre este e o valor humano da dignidade, é irrefutável que as prestações de saúde devem ser acessíveis a toda a sociedade em condições de igualdade. (VEASE INTRAND; SIMMONOT, 2009).

E mais, quando a diretiva ordena um tratamento de transtornos psíquicos graves não parece pensar, ou pelo menos na prática fica totalmente excluído, tratamento da depressão, que é a doença mais comum nos requerentes de proteção internacional. ${ }^{7}$ E deve-se mencionar também, que uma proteção da saúde real deveria passar indubitavelmente pelas condições de acolhimento em que se encontram os requerentes, por exemplo, nos campos de refugiados onde os dados do ACNUR revelam o problema. ${ }^{8}$

\footnotetext{
Entrevista com o diretor de saúde mental do ACNUR, Pieter Ventevogel: "Em geral, o que podemos dizer é que cerca de 20 por cento das pessoas deslocadas têm problemas de saúde mental, e a maioria delas, na parte leve do espectro. Penso que o maior problema de saúde mental entre os refugiados tem a ver com a perda e a dor, que por vezes pode levar à depressão. As pessoas perderam muitas coisas - é claro, entes queridos, mas também coisas materiais, e também status, coisas não materiais, ser alguém. Os refugiados tiveram muitas experiências de perda." (VENTEVOGEL, 2017).

8 De acordo com dados do ACNUR O campo Elliniko I, por exemplo (um estádio de hóquei), foi aberto em 29 de agosto de 2015. Ele abriga 1850 pessoas, embora sua capacidade seja para 1400. Tem 48 banheiros, e 12 chuveiros sem divisão entre homens e mulheres. Apenas 4 têm água quente. A distância para o centro de saúde mais próximo é de mais de 5 quilômetros. Numa situação muito semelhante encontram-se os 908 refugiados do campo de Ritsona que, embora tenha capacidade para todos eles tem apenas 10 duchas, 3 delas com água quente, e 40 banheiros.
} 


\section{A proteção da saúde como limite à expulsão}

Outra questão a considerar é a de saber se a proteção da saúde, enquanto princípio orientador necessário para a efetiva garantia dos direitos fundamentais, tal como definido pelo TEDH, pode servir de limite a uma ordem de expulsão ou devolução.

Nesta linha, o TEDH configurou uma jurisprudência tratando de estabelecer um limite à sua aplicação apenas em situações muito excepcionais em que a expulsão implique, atendendo à saúde do imigrante, violação dos artigos 2 e 3 da CEDH. Assim, o Tribunal de Estrasburgo no processo $N$. contra o Reino Unido9 deixou claro que "não existia uma obrigação por parte dos Estados contratantes de paliar as desigualdades médicas disponíveis nos Estados que implicasse o dever de fornecer cuidados médicos gratuitos e ilimitados a todos os estrangeiros sem direito a residir no seu território." Neste caso concreto, a recorrente, uma com a nacionalidade de Uganda, entrou no hospital poucos dias depois de chegar ao país, apresentando um estado grave devido a doenças ligadas à AIDS. Apresentou um pedido de asilo recusado e, durante os nove anos do processo até ao acordo do Tribunal de Estrasburgo, recebeu tratamento médico pelas autoridades britânicas; pelo que o Tribunal considerou que o Reino Unido tinha cumprido a sua obrigação de prestar cuidados de saúde a um requerente de asilo e que não incorreria em violação do artigo 3 se executasse a ordem de expulsão. Uma grande mudança jurisprudencial desde que, em 1997, no processo D. contra o Reino Unido, o Tribunal considerou ilegal a expulsão para São Cristóvão de um doente de AIDS em fase terminal. ${ }^{10}$ Neste caso, o Tribunal Europeu considerou que se viola a proibição de submeter a tratos desumanos e degradantes quando se acorda a expulsão de uma pessoa estrangeira dependente de um tratamento médico cuja interrupção o colocaria risco de grandes sofrimentos físicos e de redução da sua esperança de vida.

A jurisprudência atual também não é mais flexível no caso de doenças mentais, tendo-se procedido a expulsões mesmo quando o recorrente sofria graves tendências suicidas. Trata-se do caso Balogun/Reino Unido, de 2012, em que o Tribunal teve de avaliar se a expulsão de um cidadão nigeriano com tendências suicidas diagnosticadas constituía uma violação do artigo 3 da CEDH. Não o considerou, justificando-o tanto pelo fato de no seu país de origem existir serviços psiquiátricos competentes como pelo apoio de pessoal qualificado para a execução da ordem de expulsão.

Particularmente interessante, que exemplifica esta estrita jurisprudência, é o caso Khan contra Alemanha de 2016. ${ }^{11}$ No processo, o Tribunal Europeu dos Direitos Humanos teve de decidir sobre a ordem de expulsão de Khan, mulher de um refugiado paquistanês, que residia na Alemanha desde 1994 e que tinha sido condenada por matar um vizinho. Embora com a condenação, foi apreciado o seu estatuto de inimputável devido à grave doença mental de que padece, a sentença do

\footnotetext{
9 TEDH sentencia de 27de mayo de 2008. N. c. Reino Unido n. 26565/05.

10 TEDH sentencia de 2 de mayo de 1997. D. c. Reino Unido. La información respecto de la ejecución de esta sentencia está disponible en: https://hudoc.echr.coe.int/eng\#\{ "itemid":["001-56774"]\}.

11 TEDH sentencia de 21de septiembre de 2016. Khan c. Allemagne. 38030/12.
} 
Tribunal de Estrasburgo, embora com um parecer dissidente, aceitou a expulsão sem atender à saúde mental da recorrente e sem considerar a violação do direito à vida privada e familiar previsto no artigo 8 CEDH (MONTILLA MARTOS et al., 2016, p. ).Em suma, a linha marcada por Estrasburgo a partir da citada causa $D$. contra o Reino Unido coloca não tanto na mira os serviços de saúde que o doente vai receber no seu país de origem nem a perspectiva de futuro do mesmo, mas no estado de saúde no momento da expulsão; de tal modo que só se torne impraticável, ou seja, que o seu estado de saúde se agrave consideravelmente devido à mera transferência, seria considerada violação do artigo 3 da CEDH. Uma interpretação do conceito de tortura ou tratamento degradante que submete à ponderação, segundo o princípio da proporcionalidade, a medida a executar (expulsão), com direitos fundamentais como a vida ou a integridade. Proporcionalidade necessária em qualquer estado democrático que deve tentar evitar um mal maior do que o próprio determinado na lei. No entanto, não parece que isso seja conseguido com base nos critérios estabelecidos pelo Tribunal, o que demonstra que, em todos os acordos deste tipo, houve opiniões divergentes de juízes do Tribunal.

\section{Conclusão}

A crise econômica evidenciou a insuficiente garantia que ampara os direitos sociais, localizados em nossa Constituição sob a denominação de "princípios orientadores da política social e econômica". Uma situação estratégica que não só condiciona a sua exigibilidade a um desenvolvimento legal, mas, pior ainda, que subordina a sua exigência a que sejam economicamente suportáveis pelo Estado.

Um triste exemplo disso foi o Real Decreto-Lei n. 16/2012, cuja motivação para excluir dos cuidados de saúde um grupo tão vulnerável como os estrangeiros em situação irregular foi, unicamente, a economia financeira. $O$ direito à proteção da saúde, um direito reconhecido a todo o ser humano em numerosos textos de direito internacional, fica assim subordinado a uma simples condição administrativa e econômica. E não era a intenção deste trabalho em absoluto assinalar a incoerência desta medida ${ }^{12}$ porque, o que verdadeiramente se trata de assinalar é a inoportunidade dessa motivação já que, desde que se assinala a inegável ligação que este direito apresenta com a dignidade humana, e com a integridade física, nenhuma razão econômica deve ser empregado discriminatoriamente caso contrário seria menosprezado estima, dignidade, integridade e, a fine, a própria vida destas pessoas por sua mera condição de irregular e antepondo a isso a economia ou, nas palavras da própria STC 139/2016, "a salvaguarda das finanças do Estado".

Do mesmo modo, a proteção da saúde deve ser considerada um motivo suficiente para deter uma medida de expulsão, uma vez que não é tratada como se afirma na jurisprudência supracitada de "paliar as desigualdades médicas disponíveis nos Estados que implique o dever de fornecer cuidados

\footnotetext{
$\overline{12}$ Apesar de já ter sido referido que um estudo da Agência Europeia dos Direitos do Homem desmentiu a sua utilidade.
} 
médicos gratuitos e ilimitados a todos os estrangeiros carentes do direito de residir no seu território", 13 mas de proteger um bem jurídico tão importante como é a saúde, de uma pessoa que se encontra no seu território, sob a sua jurisdição, e à qual se deve, portanto, garantir uma vida digna.

Em suma, podemos concluir que a precária proteção deste direito se torna ainda mais evidente quando os sujeitos afetados se referem a um dos grupos mais vulneráveis: imigrantes irregulares e requerentes de proteção. Neste sentido, o controverso acórdão do Tribunal Constitucional 139/2016, que sem dúvida responde a uma interpretação economicista da Constituição, não fornece qualquer orientação interpretativa que determine constitucionalmente o que se entende por acesso universal de tal forma que se possa inferir que a universalidade terá o conteúdo que o legislador, ordinário ou de urgência, confira em cada momento (SOBRINO GUIJARRO, 2017).Evidentemente, a grave crise econômica dos últimos anos determinou uma série de medidas regressivas dos direitos sociais, mas onde está o limite? Foi a crise econômica a causa da crise do Estado social ou apenas a evidenciou? Somente está garantida a assistência sanitária em tempos de bonança econômica?

É precisamente naqueles momentos em que o Estado social está em perigo, em que o poder do Estado cede aos mercados financeiros e a economia começa a ocupar o lugar do direito, quando a jurisprudência constitucional deve concretizar esses mínimos de conteúdo essencial que devem ficar fora do alcance dos agentes políticos, pois nas palavras do Habermas (1998):

O nosso ordenamento jurídico assenta em princípios fundamentais de conteúdo universal e a realização destes princípios pode ser entendida como o esgotamento deste conteúdo. Regras como os direitos fundamentais, a garantia do processo judicial, o princípio da soberania popular, a separação de poderes, o princípio do Estado social, etc. Estão inevitavelmente formuladas num alto escalão de abstração. Estes princípios deveriam ter uma vigência universal, isto é, valer em todo momento e espaço, para tudo e para todos e também para outras normas que julgamos segundo estas medidas.

Em janeiro de 2019, a Organização Mundial de Saúde apresentou seu primeiro relatório (WORLD HEALTH ORGANIZATION, 2018) sobre a saúde dos refugiados e migrantes na Europa e afirmou enfaticamente uma ideia que não pode ser perdida de vista:

"Não pode existir saúde pública sem saúde para imigrantes e refugiados."

\section{Referências}

CÁRCAR BENITO, Jesús Esteban. "Una reflexión sobre el Derecho a la asistecia sanitaria como derecho social y Universal con financiación pública". Revista de Derecho UNED, [S. l.], n. 18, p. 191 224, 2016.

CONSTITUCIÓN ESPAÑOLA. Boletín Oficial del Estado, 29 de diciembre de 1978.

$\overline{13}$ TEDH sentencia de 27 de mayo de 2008. N. c. Reino Unido n. 26565/05. 
DELGADO DEL RINCÓN, Luis Esteban. "El derecho a la asistencia sanitaria d elos inmigrantes irregulares: reflexiones sobre la reforma introducida por el Real Decreto-Ley 16/2012, de 20 de abril". Revista de Estudios Políticos (nueva época), Madrid, n. 163, p. 189-231, enero- marzo 2014.

ESPANHA. Preámbulo del Real Decreto-ley 16/2012, de 20 de abril. Medidas urgentes para garantizar la sostenibilidad del Sistema Nacional de Salud y mejorar la calidad y seguridad de sus prestaciones.

ESPANHA. STC 139/2016, de 21 de julio 2016a. F.J 6.

ESPANHA. STC 139/2016, de 21 de julio 2016 b.F.J 8.

ESPANHA. STC 236/2007, de 7 de noviembre 2007a. FJ 3.

ESPANHA. STC 236/2007, de 7 de noviembre 2007b. FJ 4.

EUROPEAN UNION AGENCY FOR FUNDAMENTAL RIGHTS. Cost of exclusión from healthcare. The case of migrants in anirregular situation. Oficina de Publicaciones de la Unión Europea, Luxemburgo, 2015. Disponível em: http://fra.europa.eu/en/publication/2015/cost-exclusion-healthcare-case-migrants-irregular-situation. Acesso em: 19 out. 2019.

HABERMAS, Jürgen. Ensayos Políticos. Traducción: Ramón García Cotarelo. Barcelona: Ed. Península, 1998.

LUCAS MARTÍN, Javier de. "Los refugiados en la era de Trump. Un problema político, no una crisis humanitaria". In: CICLO: EUROPA FORTALEZA: FRONTEIRAS, VALADOS, EXILIOS, MIGRACIÓNS. 2017. Disponível em: http://consellodacultura.gal/mediateca/extras/Texto_javier_de_lucas_maquetado-DEFIN.pdf. Acesso em: 19 out. 2019.

LUCAS MARTÍN, Javier de. "Mediterráneo, Fosa De Inmigrantes, Refugiados Y Del Proyecto Europeo. In: CONFERENCIA MAGISTRAL EN LA FACULTAD DE CIENCIAS POLÍTICAS Y SOCIALES, UNAM, México, ago. 2016. Disponível em: http://lucasfra.blogs.uv.es/2016/08/19/ mediterraneo-fosa-de-inmigrantes-refugiados-y-del-proyecto-europeo-conferencia-magistral-en-la-facultad-de-ciencias-politicas-y-sociales-unam-mexico-12-08-2016/. Disponível em: 20 out. 2019.

MARCOS DEL CANO, Ana María. "El derecho a la protección de la salud: delimitación y alcance en el contexto actual" en El derecho a una asistencia sanitaria para todos: una visión integral". In: MARCOS DEL CANO, Ana María (Dir.). Colección Derechos Humanos y Filosofía del Derecho. Madrid: Dykinson. 2017.

MARTÍNEZ DE PISÓN, José. "El derecho a las alud: un derecho social esencial". Derechos y Libertades, Época II, [S. l.], n. , p. 129-150, enero 2006.

MONEREO PÉREZ, José Luis; TRIGUERO MARTÍNEZ, Luis Ángel (Dir. Coord.). "Refugiados y asilados ante el modelo social europeo y español. Estudio técnico- jurídico y de política del Derecho", Comares, [S. l.], 2016.

MONTILLA MARTOS, José. A. et al. "Legislación, jurisprudencia y derechos de los inmigrantes". Anuario CIDOB de la Inmigración, p. 272-293, 2015-2016.

PORRAS RAMÍREZ, José M. "Eficacia jurídica del principio constitucional de la dignidad de la persona”. Anuario de Derecho Eclesiástico del Estado, v. 34, 2018. 
SANTIAGO REDONDO, K. "Comentario al artículo 43 de la Constitución". In: COMENTARIOS A LA CONSTITUCIÓN ESPAÑOLA. RODRÍGUEZ-PIÑERO, Miguel; BRAVO, Ferrer; CASAS BAAMONDE, María Emilia (Dir.). Conmemoración del XL aniversario de la Constitución. Tomo I. Madrid: Fundación Wolters Kluwer, 2018.

SOBRINO GUIJARRO, Irene. "Contenido Constitucional del Derecho a la protección de la salud a la luz de la stc 139/2016". Ius et scientia, [S. l.], v. 31, n. 1, p. 79-88, 2017.

SOLANES CORELLA, Ángeles. "La salud como derecho en España: reformas en un contexto de crisis económica". Derechos y libertades, Época II, [S. l.], n. 31, , jun. 2014. .

VEASE INTRAND, Caroline; SIMMONOT, Nathalie. "L'Europe et les sans-papier- Politique de santé ou politique d'immigration?" Revue Homes et Migrations, n. 1282, 2009.

VENTEVOGEL, Pieter. Entrevista: Lejos de estar traumatizados, la mayoría de los refugiados son "sorprendentemente resilientes". [Entrevista cedida a] Tim Gaynor. ACNUR, 3 enero 2017. Disponível em: http://www.acnur.org/noticias/noticia/entrevista-lejos-de-estar-traumatizados-la-mayoria-de-los-refugiados-son-sorprendentemente-resilientes/. Acesso em: 20 out. 2019.

WORLD HEALTH ORGANIZATION. Report on the health of refugees and migrants in the WHO European Region. 2018. Disponível em: https://apps.who.int/iris/bitstream/handle/10665/311347/ 9789289053846-eng.pdf? sequence=1\&isAllowed=y. Acesso em: 19 out. 2019. 
